\title{
PERCEPÇÕES DOS INTEGRANTES DE UM PROJETO SOCIAL DE EDUCAÇÃO E ESPORTE EM FLORIANÓPOLIS (SC) ${ }^{1}$
}

Recebido em: 07/08/2016

Aceito em: 25/04/2017

\author{
Liliana Flora \\ Universidade Estadual de Santa Catarina (UDESC) \\ Florianópolis - SC - Brasil \\ Miraíra Noal Manfroi \\ Verônica Werle \\ Universidade Federal de Santa Catarina (UFSC) \\ Florianópolis - SC - Brasil \\ Alcyane Marinho \\ Universidade Estadual de Santa Catarina (UDESC) \\ Florianópolis - SC - Brasil
}

RESUMO: Este estudo teve por objetivo investigar um Projeto social esportivo em Florianópolis (SC), sob o olhar dos seus integrantes. Participaram da pesquisa educandos assíduos do Projeto, há dois anos ou mais, e educadores contratados para trabalharem no mesmo. Os instrumentos utilizados foram observações e entrevistas semiestruturadas, sendo que os dados coletados foram analisados por meio da técnica de análise de conteúdo. Os resultados evidenciaram a predominância do esporte educacional e dos valores sociais como conteúdos; a valorização da participação do educando, embora ainda seja necessária a consolidação desta prática; a manifestação sobre os significados do Projeto vinculada às relações afetivas ali estabelecidas; a possibilidade de uma educação para o lazer; e, por fim, o reconhecimento sobre a necessidade de maior diálogo com as famílias dos educandos e o entendimento sobre sua realidade.

PALAVRAS CHAVE: Projetos. Esportes. Educação.

\section{PERCEPTIONS OF THE MEMBERS OF A SOCIAL PROJECT OF EDUCATION AND SPORT IN FLORIANOPOLIS (SC)}

ABSTRACT: This study aimed to investigate a social sports project in Florianópolis (SC), from the perspective of its members. The participants were the assiduous students, for two years or more, and working educators. The instruments used were observations and semi-structured interviews, and the data were analyzed using content analysis technique. The results demonstrate the predominance of educational sports and social values; the appreciation of the student's participation, even though this practice needs to be reinforced; the Project meanings is linked to emotional

\footnotetext{
${ }^{1} \mathrm{O}$ nome do projeto investigado não foi identificado com o intuito de preservar sua identidade.
} 
relationships established; the possibility of "education for leisure"; and, finally, recognition the need of more dialogue with the students families and better understanding of student reality.

KEYWORDS: Projects. Sports. Education.

\section{Introdução}

Conheça todas as teorias, domine todas as técnicas, mas ao tocar uma alma humana, seja apenas uma alma humana. Carl G. Jung

No Brasil, os projetos sociais existem desde o final da década de 1920 e, com o passar dos anos, essas iniciativas foram alvo de muitas polêmicas. Por um lado, o aumento destas ações nas últimas décadas pode ser encarado como um reflexo positivo de uma maior mobilização e organização da sociedade civil, por outro, são recorrentes as críticas devido ao envolvimento duvidoso de políticos e o predomínio de interesses particulares (MELO, 2008; SILVEIRA, 2013). Nestes casos, Melo (2008) destaca que nem sempre os objetivos e os investimentos visam o público-alvo e a inclusão e, sim, os descontos fiscais ou a construção de uma imagem positiva para a empresa ou instituição proponente, vinculada a causas sociais. Apesar disso, há de se considerar que também existem muitos projetos sociais que têm realizado práticas efetivas e eficientes em se tratando dos objetivos por eles divulgados.

Com a finalidade de orientação teórica-conceitual deste estudo foi eleita a perspectiva de projeto social indicada por Armani (2001). De acordo com este autor, os projetos sociais iniciam com uma ideia, um desejo ou um interesse em realizar algo, que se expressa por meio de um esquema lógico que sempre será um esboço provisório, pois, sua implementação exige constante aprendizado e reformulação. 
Trata-se, portanto, de uma ação planejada, com objetivos, resultados e atividades que dialogam com os recursos disponíveis (humanos, materiais e financeiros) e do tempo.

O autor observa a necessidade de uma cultura de gestão destes projetos, na qual se incluem atitudes de reflexão crítica, de aprendizado e de investigação permanente. Neste sentido, é importante a inclusão de ferramentas e dinâmicas para a participação de todos os envolvidos, além de uma postura flexível, favorável para a experimentação, adaptação e inovação, implicando em maiores chances de êxito no desenvolvimento do projeto (ARMANI, 2001).

Apesar das inúmeras dificuldades, existem algumas estratégias que potencializam o alcance dos objetivos destes projetos, como é exemplo a implementação do gerenciamento sistemático e participativo (ARMANI, 2001). São ações que mobilizam mais indivíduos para participar, promovem parcerias e motivam o grupo participante, facilitando a administração dos recursos disponíveis, sejam de origem pública ou privada, favorecendo a participação efetiva de todos os setores envolvidos com a ação e aumentando a chance de parcerias, resultando em mudanças mais duradouras e sustentáveis nos beneficiários e no contexto onde o projeto se desenvolve.

Sejam por meio da iniciativa pública, organizações não governamentais (ONGs) ou empresas privadas, muitos projetos sociais têm assumido a tarefa (ou a intencionalidade) de promover a cidadania, a inclusão social ${ }^{2}$ e a educação, tendo como instrumento privilegiado os elementos da cultura de movimento, como o

\footnotetext{
${ }^{2}$ Promoção da cidadania e inclusão social são termos frequentes na descrição da justificativa e dos objetivos dos projetos sociais, embora estes nem sempre consigam superar o modelo, no qual um conjunto de atividades é aleatoriamente selecionado para ocupação do tempo dos participantes. Compondo a herança cultural brasileira, as práticas esportivas e de lazer constituem os direitos sociais, que em conjunto com os direitos civis e políticos formam a noção de cidadania, conforme explica Menicucci (2006) apoiada no trabalho de Marshall. A formação cidadã não se dá, no entanto, apenas com acesso a tais direitos, mas a partir da construção da autonomia e da participação crítica do indivíduo junto aos objetos culturais, de modo a oportunizar sua maior inserção social e, segundo Menicucci (2006), reduzir sua dependência em relação ao mercado.
} 
esporte, a dança e os jogos e brincadeiras. Embora seja comumente atribuído aos conteúdos destes projetos o caráter salvacionista, eles não se constituem em uma fórmula mágica por si só.

Sabe-se que, em muitas situações, os projetos destas áreas carecem de conhecimentos que vão além da área específica de atuação da educação física e que permitiriam objetivos mais amplos se efetivarem, sendo necessário, portanto, tencionar a relação, geralmente linear, estabelecida entre esporte e formação cidadã, como aponta Neira (2009), entendimento que se acredita circular, não apenas no senso comum, mas entre os próprios profissionais da área.

Nesta perspectiva, Zingoni (2007) reforça que os reflexos dos conhecimentos sistematizados nos projetos sociais ainda são fracos, mesmo com boas intenções os objetivos dificilmente são alcançados em sua totalidade sem uma análise permanente e criteriosa, e de uma intervenção organizada. A autora enfatiza a necessidade do desenvolvimento de uma cultura voltada para elaboração, mas também para o monitoramento e avaliação do projeto no sentido de buscar seu constante aperfeiçoamento, corrigindo e melhorando o que for necessário.

Complementando estas compreensões, Melo (2008), assim como Armani (2001), argumenta que se faz necessário que os projetos deste caráter sejam desenvolvidos pela sociedade como um todo, por diferentes atores, setores e instituições. $\mathrm{O}$ autor também alerta sobre a visão geral de que projetos sociais são exclusivamente desenvolvidos em comunidades de baixa renda e/ou com pessoas 
excluídas $^{3}$ da sociedade, tornando modismo realizar o "social" no Brasil. O cuidado inserido nesta crítica é, novamente, a necessidade de tencionar o entendimento generalizado de que ações adjetivadas de sociais, independentemente da forma como são implementadas, por si só, carregam algo de positivo, além de serem suficientes para dar conta de complexos problemas sociais que são estruturais no país. Tendo isto em vista, procurou-se tratar esta temática com cautela ao longo deste texto, refletindo no âmbito das contribuições pontuais e contextualizadas que cada projeto pode fornecer.

Sendo o esporte um dos pricipais conteúdos veiculados nos projetos sociais, e sabendo das múltiplas abordagens com que ele se manifesta, destaca-se a sua subdivisão em, pelo menos, três segmentos: o esporte educação, o esporte lazer e o esporte de desempenho, conforme proposto, historicamente, por Tubino (2006; 2010). Porém, sabe-se que, de uma forma geral, os projetos sociais têm focalizado o primeiro segmento, o que se reproduz no Projeto investigado neste estudo.

Conforme descreve Tubino (2006; 2010), o esporte educação se refere a uma modalidade praticada durante a infância e a adolescência dentro e/ou fora da escola. Está subdividido em esporte educacional e esporte escolar, sendo que o primeiro possui características socioeducativas e é baseado em princípios como participação, cooperação, coeducação, integração e corresponsabilidade, podendo ser ofertado tanto no ambiente escolar como fora dele. O esporte escolar tem como propósito o desenvolvimento esportivo e o espírito esportivo, tendo seu espaço de

\footnotetext{
${ }^{3}$ Embora a opção do autor seja utilizar o termo "excluídos" para se referir a grupos sociais com menos condições de acesso aos direitos e à participação social, seja em virtude da situação financeira, etnia, opção sexual e gênero, entende-se que estes grupos são constitutivos da sociedade, e não algo "fora" dela. Assim sendo, entende-se como mais apropriado, neste caso, o uso do termo "minorias", alternativa provisória, que não esgota a necessidade de maior aprofundamento do conceito de exclusão. Para tanto, sugere-se o trabalho de Oliveira (1997), que se propôs a construção epistemológica e sociológica do termo.
} 
desenvovimento prioritariamente no ambiente escolar, sendo que nos dois segmentos se objetiva a formação para a cidadania (TUBINO, 2006; 2010).

Embora proponha estas três categorias do esporte, Tubino $(2006 ; 2010)$ analisa que o esporte educação, em uma perspectiva sistêmica, mantém-se constantemente ligado às outras categorias, na medida em que aqueles que têm acesso a ele ainda na infância, futuramente poderão praticar o esporte no lazer e, ainda, poderão acessar ao esporte de desempenho. Por outro lado, o autor entende que o esporte de desempenho tem ligação com os demais na medida em que os seus atletas, "modelos de sucesso", podem incentivar, em certa medida, o esporte educação e o esporte lazer. Salienta-se que, a partir dessas relações estabelecidas por ele, exista um ciclo do esporte contemporâneo, em que o esporte educação pode ser o alicerce fundamental (TUBINO, 2010).

Torna-se claro, portanto, a necessidade do emprego do esporte educação, mais especificamente o esporte educacional, como eixo para o desenvolvimento de projetos sociais. Sem desprezar as categorias criadas por Tubino, que podem ser explicadas historicamente, mas redimensionando o assunto, é importante elucidar a reflexão de outros estudiosos do esporte ao advertirem que toda a prática esportiva pode ser educacional, dependendo da maneira como é conduzida (BRACHT, 2003; GONZÁLES et al., 2014).

Paralelamente a estas considerações iniciais e outras inquietações individuais, uma série de questionamentos motivou o início do estudo desta temática, entre eles: como os projetos sociais se configuram na sociedade atual? Quais relações são estabelecidas entre projetos sociais, esporte e lazer? Como as crianças e/ou adolescentes percebem o Projeto social do qual participam na realidade de Florianópolis (SC)? O que faz com que os participantes permaneçam no Projeto? 
A partir destes questionamentos preliminares, a pesquisa propôs a investigação de um Projeto social caracterizado por trabalhar com esporte educacional, em Florianópolis (SC). A despeito da ampla discussão que tem sido feita sobre a transferência das funções do Estado, no que tange as políticas sociais para o chamado terceiro setor e organizações não governamentais - ONGs (SILVEIRA, 2013), como se caracteriza a Instituição da qual o Projeto aqui investigado faz parte, neste trabalho, a tarefa proposta é olhar para o interior do Projeto e refletir, a partir de seus atores, sobre as potencialidades engendradas no processo de formação esportiva e cidadã ${ }^{4}$, bem como sobre possíveis contribuições de suas formas organizacionais e estruturais para a eficiência de ações sociais como um todo.

Ao mesmo tempo, não se deixará de observar e refletir sobre os desafios que projetos desta natureza enfrentam, independentemente da instituição ou órgão promotor, e que se apresentam como desafios para o Estado e para a sociedade em geral. Portanto, como objetivos específicos, este estudo propôs-se a: analisar a percepção dos educandos sobre os conteúdos desenvolvidos no Projeto; observar a participação dos educandos na construção das atividades propostas; refletir sobre os significados atribuídos ao Projeto pelos educandos; bem como investigar a percepção dos educadores sobre o mesmo.

\section{Abrindo as Portas do Projeto}

O Projeto Social investigado faz parte de um Programa desenvolvido por uma associação civil situada na cidade de Florianópolis (SC), desde 2000. Sem fins lucrativos e de caráter filantrópico, a associação tem suas atividades integralmente

\footnotetext{
${ }^{4}$ A formação cidadã desenvolvida no projeto estudado vai ao encontro da reflexão de Melo (2008, p. 9) que a descreve como sendo a capacidade de o sujeito "[...] desenvolver olhares críticos sobre a realidade que os cerca, não adaptação incondicional a esse modelo de sociedade [...]", ou seja, que ao despertar da consciência dos educandos em relação aos seus direitos e deveres, eles consigam ter a capacidade de questionar e transformar a sociedade e não somente acatar as regras instituídas que podem, por vezes, levar a uma injustiça social.
} 
patrocinadas e apoiadas por instituições privadas. O Programa aqui investigado tem como objetivo o desenvolvimento pessoal e social de crianças e adolescentes no sentido de dar as condições para o pleno exercício da sua cidadania, por meio de diversas ações educativas, esportivas e sociais.

Dentre as ações deste Programa foi investigado, mais especificamente, um Projeto Social que teve sua criação em 2002 e, atualmente, é dividido em sete núcleos situados no Estado de Santa Catarina, e distribuídos entre as cidades de Florianópolis, São José, Biguaçu, Palhoça e Campos Novos. O estudo foi desenvolvido em um destes núcleos, que, assim como os demais, tem suas atividades desenvolvidas em um local cedido por um clube ou empresa, sendo que apenas um dos núcleos necessita alugar um espaço. Como um todo, este Projeto atende 720 educandos ${ }^{5}$, sendo 700 crianças e adolescentes em condições de vulnerabilidade social, econômica ou educacional $^{6}$ e 20 adultos com deficiência intelectual e física, estes últimos fazem parte do chamado Grupo Inclusivo. Com exceção do Grupo Inclusivo, cada núcleo atende 100 educandos (50 no período matutino e 50 no período vespertino) duas vezes por semana, sempre no contra turno escolar. Além de viverem sob alguma condição de vulnerabilidade, também é necessário que o educando esteja matriculado em uma escola pública próxima do núcleo do Projeto do qual pretende se inserir.

Fazem parte da iniciativa cerca 65 funcionários, sendo eles educadores, estagiários, voluntários e profissionais administrativos. No núcleo investigado há seis funcionários, sendo dois profissionais de Educação Física, um profissional de

\footnotetext{
${ }^{5}$ É importante esclarecer que neste Projeto Social, as crianças e adolescentes são chamadas de educandos, e os professores de educadores, sendo, portanto, esta nomenclatura adotada na escrita do presente trabalho.

${ }^{6}$ De acordo com Oviedo e Czeresnia (2015, p.10), "a vulnerabilidade se configura em uma dinâmica de interdependências recíprocas que exprimem valores multidimensionais - biológicos, existenciais e sociais. Uma situação de vulnerabilidade restringe as capacidades relacionais de afirmação no mundo, incluídas as formas de agência social, gerando fragilização".
} 
Pedagogia, um estagiário de Educação Física, um estagiário de Psicologia e um estagiário de Serviço Social.

As atividades do Projeto são desenvolvidas em três oficinas: de Tênis, de Esportes Complementares e Culturais, sendo que um profissional de Educação Física é fixo na Oficina de Esportes Complementares, um profissional de Educação Física é fixo na Oficina de Tênis, um profissional de Pedagogia é fixo na Oficina Cultural e os estagiários trocam de oficina a cada duas semanas.

Uma das características do Projeto é o desenvolvimento de um trabalho interdisciplinar dentro das oficinas, envolvendo seus educadores que possuem formações em diferentes áreas, como anteriormente mencionado. As três oficinas têm objetivos educacionais, que variam de acordo com o subtema aplicado e/ou as demandas dos educandos, como utilizam estratégias diferentes para alcançar esses objetivos. Na Oficina de Tênis os educandos aprendem as regras e os fundamentos básicos do jogo. Na Oficina de Esportes Complementares são promovidas diversas modalidades esportivas e recreativas. Por sua vez, a Oficina Cultural utiliza recursos, normalmente, não esportivos, para alcançar seus objetivos educacionais: desenho, pintura, produção artesanal, teatral, artística em geral, produção de folders, brincadeiras diversas, jogos, entre outras estratégias. Para que possam circular nas três oficinas no período em que se encontram no Projeto, os educandos são divididos em três turmas, de acordo com a idade, entre Turmas A (de 7 a 9 anos), B (de 10 a 12 anos) e C (de 13 a 15 anos).

Outras ações significativas do Projeto são as atividades de leitura promovidas pela biblioteca motorizada itinerante, as reuniões de pais (que acontecem a cada semestre) e os eventos. Entre estes estão: o Encontro de Integração dos Núcleos Esportivos, evento que reúne todos os núcleos do Projeto (com exceção de um, devido 
à distância) com jogos, atividades esportivas e recreativas; o Torneio de Tênis entre os educandos de todos os núcleos; a Semana da Família, em que familiares dos educandos podem ir aos núcleos ver e participar das oficinas com os filhos; o Dia do Amigo, em que os educandos podem levar um amigo para os núcleos; além dos passeios realizados durante o ano.

Observou-se que há um conjunto de regras de convívio que devem ser cumpridas pelos educandos e que são constantemente destacadas pelos educadores, sendo exemplos: usar colete de identificação correspondente ao núcleo, usar roupas adequadas para a realização das atividades, amarrar os cabelos compridos, respeitar os educadores e os outros educandos, além de não ser permitido o uso de palavrões e ofensas. Também é realizado o controle de frequência dos educandos, sendo que no caso de três faltas seguidas sem justificava ocorre a perda da vaga.

Quinzenalmente é realizada uma reunião com todos os educadores e profissionais envolvidos, com a finalidade de avaliar as atividades realizadas, discutir os relatos e encaminhamentos de caráter domiciliar e escolar realizados pela Assistente Social, debater sobre a avaliação da Psicóloga sobre os educandos, realizar o planejamento quinzenal das três oficinas a partir de subtemas e, por fim, socializar o planejamento com todos os profissionais.

Outra característica do Projeto investigado é o trabalho estruturado nos Quatro Pilares da Educação nomeados como "aprender a conhecer", “aprender a fazer", “aprender a viver juntos" e "aprender a ser" 7 . Entre inúmeras discussões, o documento que embasa o trabalho nos Quatro Pilares aborda a utilização do esporte como componente motivador para auxiliar na educação, no aprendizado e na

\footnotetext{
${ }^{7}$ Os Quatro Pilares da Educação são desenvolvidos no Relatório para a UNESCO da Comissão Internacional sobre Educação para o Século XX. Coordenado por Jacques Delors, o relatório foi editado na forma de livro em 1999 e reeditado em 2012, sendo um capítulo inteiro dedicado à discussão dos Quatro Pilares da Educação.
} 
cidadania do educando, além de destacar a importância do diálogo entre a escola e os familiares dos educandos.

\section{Caminhos da Investigação}

A pesquisa ${ }^{8}$ foi desenvolvida a partir da perspectiva qualitativa de investigação que, de acordo com Minayo (2012), responde a questões bastante particulares, preocupando-se com a realidade que não pode ser quantificada, e trabalhando, dessa forma, com um universo de significados, motivos, aspirações, crenças, valores e atitudes. Também é características da pesquisa qualitativa o espaço aberto para a intuição, a exploração e a subjetividade, permitindo maior aprofundamento nos significados das ações e relações humanas.

Foram convidados a participar desta pesquisa 20 educandos que frequentavam o núcleo do Projeto há pelo menos dois anos com assiduidade. Além deles, fizeram parte do estudo três educadores, todos do mesmo núcleo. Os instrumentos de coleta de dados utilizados foram a entrevista semiestruturada e a observação participante. A primeira foi organizada a partir de um roteiro com perguntas previamente formuladas, havendo a possibilidade de alterações e acréscimos de questões (MINAYO, 2012).

Foram realizadas 20 entrevistas com os educandos sendo 10 meninas e 10 meninos, entre nove e 14 anos. Também foram realizadas entrevistas com três educadores, uma pedagoga e dois professores de Educação Física com idades entre 24 e 29 anos. As entrevistas foram agendadas em data, horário e local compatíveis com a disponibilidade dos mesmos, sendo realizadas individualmente, em um espaço reservado e, registradas por meio de um gravador de áudio, seguindo-se à sua transcrição.

\footnotetext{
${ }^{8}$ Submetida e aprovada pelo Comitê de Ética em Pesquisas com Seres Humanos (CEPSH) da Universidade do Estado de Santa Catarina, sob número: 052464/2015.
} 
A técnica de observação, por sua vez, consistiu em ver, ouvir e examinar a realidade que se está estudando, conforme estabelecem Lakatos e Marconi (2007). Como indicam os autores, a observação participante tem como objetivo o registro e o acúmulo de informações, desempenhando um papel relevante no contexto da descoberta e requerendo que o investigador tenha contato direto com o contexto a ser pesquisado. A observação foi realizada nos dias e horários em que as crianças e adolescentes estavam presentes no Projeto, quartas e sextas feiras, períodos matutino e vespertino, durante um mês. Para registro das observações foi utilizado um diário de campo.

Finalizada a coleta de dados, procedeu-se com as análises dos mesmos por meio da técnica de análise de conteúdo. Assim, seguindo as orientações Bardin (2009), os dados foram organizados a partir da sistematização e descrição dos seus conteúdos seguindo três etapas de análise denominadas pré-análise, exploração do material e, tratamento dos resultados e inferência e interpretação.

\section{Entre o Esporte Educacional e os Valores Sociais: Os Conteúdos do Projeto}

Inicialmente, constatou-se que o Projeto abrangia diferentes conteúdos a partir de distintos momentos em que eram divididas as atividades, a saber: Oficina Cultural, de Tênis e de Esportes Complementares. De fato, a fala dos educandos mostrou haver coerência entre o discurso oficial e o conteúdo desenvolvido, uma vez que as atividades mais citadas foram o tênis, o futebol e o voleibol, assim como, brincadeiras e desenhos, perceptível na fala do educando Matheus "As atividades que eu faço aqui incentivam muito lá fora e são bem legais. Na Oficina Cultural o melhor é desenhar [...] na Esportes Complementares tem futebol e outras atividades e na de Tênis a gente

\footnotetext{
9 Os participantes do estudo estão sendo tratados por nomes fictícios, para garantir a preservação de suas identidades.
} 
aprende os fundamentos do tênis." A fala de Eliane também expõe os conteúdos: "Eu brinco, faço esportes, tem a Oficina Cultural, que eu gosto bastante, mas a que eu mais gosto é a Oficina de Tênis porque lá a gente aprende muitas coisas, na hora do intervalo a gente brinca de vôlei e outras coisas.".

No caso específico de se trabalhar o esporte educacional, González et al. (2014) refletem que os legados deixados dependem, fundamentalmente, dos sujeitos envolvidos na prática social (educadores, as suas intenções e ações) e não da prática social somente (esporte). Portanto, é inviável pensar no legado sem refletir sobre a formação dos educadores e sua atuação.

Nesta mesma direção, Darido (2012) aponta que o esporte, por ele mesmo, não é educativo, sendo necessário que haja uma intervenção para que tenha esse enfoque. Assim, a autora ressalta que o esporte possui grandes possibilidades de ser trabalhado neste viés, mas que realmente dependerá de como esse processo é conduzido pelo educador, pois, argumenta que o fato de o esporte ser praticado não significa que está havendo o aprendizado do esporte educacional.

A necessidade de se estar atento para a atuação do educador é muito evidente, pois quando perguntado aos educandos sobre o que mais gostavam no projeto, quase unanimemente, foi o tênis, e percebe-se que, pelas análises de suas respostas, não é unicamente o conteúdo (tênis) que mais as encanta, mas a forma como o educador trabalha este esporte. Como exemplo, Beatriz coloca: "[...] porque a gente joga no sol, vai pra campeonato, o professor ensina a gente a jogar, é bem legal.”; e da educanda Eliane: “[...] porque eu nunca joguei tênis na minha vida, e, quando eu entrei neste Projeto, eu aprendi várias coisas. Eu estou gostando bastante do tênis porque o professor é ótimo pra ensinar e, quando eu não sei alguma coisa, ele ajuda também.”. 
Pela fala dos educandos, nota-se um olhar delicado e atencioso do educador que desenvolve a modalidade de tênis neste projeto. $O$ educador usa seu conhecimento para planejar e desenvolver as atividades da oficina, mas também usa da paciência, dedicação e carinho pelo esporte e pelos educandos, para que todos consigam aprender e gostar da modalidade. Em diversos momentos foi possível observar este professor parando para conversar com algum educando ou, até mesmo, deixando os mais experientes praticando entre si e dando mais atenção a um educando com mais dificuldade na modalidade, jogando e ensinando de maneira didática. Para além das entrevistas realizadas, os registros das observações permitem afirmar que o esporte acaba sendo o motivo que mais atrai as crianças e os adolescentes para o Projeto, sendo o tênis a modalidade mais comentada pelos educandos.

Tendo em vista a quase inexistência do tênis como conteúdo da grade curricular das escolas brasileiras, bem como os altos investimentos financeiros para a aprendizagem em instituições particulares, é provável que os educandos não teriam contato com este esporte se não fosse pela participação no Projeto. Portanto, o tênis parece ser um fator importante para a permanência dos educandos. Esta evidência é reforçada pelo que foi identificado em um estudo realizado por Eiras et al. (2010), no qual os motivos de ingresso e permanência de crianças e adolescentes em projetos sociais referem-se justamente ao conteúdo esportivo. Os autores citam investigações, realizadas por Zaluar (1994), em dois programas educativos governamentais: o Programa Privado de Iniciação Esportiva (PRIESP) e o Projeto do Irmão Menor (PIM).

Quanto ao PRIESP, Zaluar (1994) identificou que grande parte das crianças e dos adolescentes participantes havia procurado o Programa por terem o desejo de aprender e/ou praticar um esporte e ter alguma ocupação em seu tempo livre, sendo 
estes, temas recorrentes nas entrevistas. Em relação ao PIM, a autora relata que a vontade de querer aprender mais profundamente sobre um esporte e o carinho pelo mesmo, mostrou-se como uma das razões mais significativas para o envolvimento de crianças e adolescentes. Mesmo o PIM priorizando atividades recreativas, técnicas artesanais e o ensino profissionalizante, o esporte continuava sendo o elemento mais procurado neste programa (ZALUAR, 1994).

Procurando tencionar essa questão, Silveira (2013) e Melo (2008) advertem que os projetos sociais e o esporte "tornaram-se" excelentes meios para resolver problemas sociais que afetam principalmente crianças e jovens. Essa colocação provoca a reflexão que o acesso é, sim, importante e que pode trazer muitos benefícios para os envolvidos, mas que crianças e jovens possuem inúmeras demandas durante esse período de suas vidas e não é somente nos projetos sociais e pelo esporte que serão atendidos. Dessa forma, torna-se importante continuar estimulando-as a participar dessas iniciativas, mas também ensiná-las sobre a gama de direitos e deveres e a necessidade de lutarem por eles.

Assim sendo, o esporte educacional, se realizado a partir de uma intenção organizada, unido com situações do cotidiano, problematizações, diálogo e busca por soluções, como orienta Neira (2009), capacita a criança ou o adolescente, como educando, para o desenvolvimento de competências técnicas (fundamentos de esportes como chute, passe, finta, manchete, controle de bola, entre outros), assim como para a participação na vida social, cultural, esportiva e no convívio com os semelhantes.

Portanto, quando se trabalha com o esporte educional, como no caso do Projeto investigado, é imprescindível saber "aonde" se quer chegar. Neste sentido, concorda-se com a reflexão de González et al. (2014, p.42-43): 
[...] desejamos que o desenvolvimento de experiências esportivas educadoras calha na constituição de um corpo de conhecimentos que transformem o conceito teórico em experiências e vivências que conduzam o aluno à busca da emancipação, da autonomia, do discernimento e, por consequência, da capacidade de intervir e de alterar a realizade social em que está inserido.

Para além do conteúdo físico e esportivo, os educandos também citam aprendizagens relacionadas a valores, comportamentos e sentimentos, sejam vinculados à atividade prática em alguma Oficina, na discussão do subtema da semana ou pela mediação de algum professor. As respostas foram variadas, mas os aprendizados mais citados foram o respeito ao próximo, a convivência com outras pessoas e "ter mais calma". O educando Christian comenta que, no Projeto, aprendeu a "Respeitar o próximo, a conviver e a fazer novos amigos."; o educando Afonso também afirma que aprendeu a "Respeitar e conviver com as pessoas.". Este aspecto é confirmado pelos educadores que dizem observar a maioria dos educandos apresentar melhoras não apenas nos aspectos físicos e motores, mas também nos aspectos emocionais e disciplinares durante sua passagem pelo Projeto. Como exemplo, os educadores citam que alguns educandos demonstravam dificuldade em lidar com situações de "ganhar ou perder" uma competição, um jogo ou uma simples brincadeira, brigavam constantemente por esse motivo e, com o passar do tempo e a com as atividades do Projeto, tais educandos começaram a ter mais calma, manter o controle e valorizar a prática esportiva como um todo, pela satisfação que traz independentemente dos resultados.

Assim como apontaram diversos pontos positivos que são desenvolvidos no Projeto, como os supracitados, os educandos também apresentaram em suas falas aspectos que não gostam muito. Dentre os mais citados estão momentos que envolvem a escrita e as gincanas. Em relação à primeira, César diz "Não gosto de 
escrever na [Oficina] Cultural porque eu já escrevo na escola." e o educando Christian reforça "Não gosto de escrever porque eu erro muito nas palavras.".

Ressalta-se que a escrita não é propriamente um conteúdo trabalhado no contexto investigado, aparecendo apenas como parte de alguma brincadeira, jogo ou momento de reflexão, nos quais é solicitado ao aluno que escreva sobre algum sentimento, experiência, desejos, dúvidas, etc. Mesmo assim, é percebida como algo desagradável pelos educandos.

Frente a esta realidade, e ao se reconhecer que a escrita e a leitura, muitas vezes, andam de mãos dadas, Freire $(1989$, p.9), alerta que “[...] ato de ler, $[\ldots]$ se antecipa e se alonga na inteligência do mundo. A leitura do mundo precede a leitura da palavra, daí que a posterior leitura desta não possa prescindir da continuidade da leitura daquele.”. Nesta perspectiva, não se nega a importância do desenvolvimento da escrita e da leitura da palavra, mas também não se negligencia que a alfabetização na infância se dá com:

[...] a leitura de si próprio, a leitura do outro e a leitura do mundo que está à sua volta. Sem o tempo para essa alfabetização social, [...] dentro do universo da oralidade, estaremos comprometendo toda a aprendizagem de sentido que o domínio de uma língua exige (PEREIRA, 2013, p.129).

A partir destas reflexões o que se compreende é que, mesmo o Projeto Social investigado tendo a intenção de oportunizar uma amplitude na leitura de mundo destes educandos, e muitas vezes conseguindo, talvez para a leitura e escrita da palavra ainda não foi encontrado um caminho significativo para desenvolvê-las, por isso o desgosto por essa atividade. Mas este não deve ser um fator de preocupação, pois corroborando com os autores (FREIRE, 1989; PEREIRA, 2013), reflete-se que por meio da participação no Projeto, da realização das atividades, das trocas entre educadores e educandos, que acabam sendo oportunidades de ampliação da leitura de 
mundo e da alfabetização social, possivelmente os educandos serão influenciados, positivamente, a desenvolverem a leitura e escrita da palavra.

Seguindo para o segundo ponto destacado pelos alunos, a gincana, mesmo sendo uma proposta de atividade lúdica e divertida, no Projeto estudado os momentos reservados para elas são marcados por conflitos e descontentamentos. A educanda Jéssica explica seu o motivo de não gostar desta atividade: “[...] porque os times ficam desorganizados.”. Essa é uma reclamação constante dos educandos, pois, normalmente, as equipes são compostas por educandos de todas as turmas (A, B, C), ou seja, com grande diferença de idade, e os mais velhos acabam não gostando dos mais novos em sua equipe, o que foi observado tanto nas entrevistas quanto em conversas informais com os educandos. Os educandos da Turma A ainda estão em estágio precoce de iniciação esportiva e, em certas atividades, não conseguem ter os mesmos níveis de habilidade dos mais velhos, o que acaba gerando algumas brigas e exclusões entre os educandos.

Durante o tempo de pesquisa no Projeto, em conversas informais com os educadores, percebe-se que eles buscam por uma solução para os conflitos no desenvolvimento das gincanas, mas que permita a participação efetiva de todos. Há discussões entre os educadores, e com os educandos, para encontrar uma solução e para continuar com gincanas no núcleo e com a participação de todos os educandos, sem exclusões e brigas. Até o final das coletas, não foi possível acompanhar uma gincana em que fossem aplicados novos direcionamentos para os problemas verificados, mas o fato de os educadores estarem refletindo sobre essa prática dentro do Projeto pode ser considerado um passo importante para as mudanças neste aspecto.

Ao fazer uma relação dos achados neste tópico com o objetivo geral do Projeto Social que é, conforme informado no seu sítio eletrônico "promover, através de ações 
educacionais e esportivas, o desenvolvimento pessoal e social, de crianças e adolescentes, contribuindo para a construção de uma visão mais ampla da realidade em que estão inseridos, na busca do exercício pleno de sua cidadania” ${ }^{10}$, percebe-se que há uma constante preocupação para que este seja alcançado, pela forma como os conteúdos são trabalhados. Sabe-se que os conteúdos por si só não dão conta de atingir esse objetivo educacional, mas se constituem como um começo importante se aliado às outras ações e ao envolvidos de todos seus integrantes.

\section{Participação: Diferentes Formas de Expressão e Construção da Cidadania}

Ao buscar-se identificar e compreender a participação, ou não, dos educandos na construção e (re)elaboração das atividades, foram evidenciadas divergências entre as respostas dadas por eles nas entrevistas e a observação das suas condutas no desenvolvimento das atividades. Embora a maioria tenha respondido não participar do processo de elaboração ou de sugestões de atividades, diversas situações observadas mostraram que eles têm participação sobre as oficinas e atividades, e suas colocações são no sentido de melhorar o que está sendo feito ou solicitar uma atividade em para um momento futuro. São exemplos desta participação a situação em que um aluno aproximou-se de um educador para pedir que fosse realizada com mais frequência a brincadeira "queimada tradicional" e "queimada paulista", e quando, em outro momento, um aluno pediu para que fosse realizada uma atividade relacionada ao parkour $^{11}$.

Observou-se que a participação dos educandos é mais frequente quando algum educador a solicita formalmente. Há, inclusive, momentos bem específicos, em

\footnotetext{
${ }^{10}$ Informações coletadas do site do Projeto, cuja referência não será exposta para manter o sigilo sobre a instituição.

${ }^{11}$ Proveniente da palavra francessa parcours ou l'art $d u$ déplacement (percurso ou arte do deslocamento), tem como objetivo mover-se de um ponto a outro com rapidez e eficácia, utilizando todas as capacidades motrizes do corpo humano.
} 
formato de rodas de conversas, em que os educandos são estimulados a discutir sobre o desenvolvimento da aula, solicitar algumas atividades e sugerir melhorias. Nestas situações, praticamente todos os educandos se manifestavam com, no mínimo, uma proposta, que era analisada pelo educador, sozinho ou em conjunto com os outros educadores, e, quando possível, aplicada na Oficina.

Diferentemente do que acontece em muitos contextos, os momentos de abertura à participação não foram realizados em datas comemorativas, a fim de "premiar" os educandos, mas foram em datas comuns, com o intuito de melhorar as atividades em si e promover a auto avaliação por meio do diálogo entre os educadores e educandos. Por vezes, esta estratégia assumia o caráter de negociação, principalmente quando havia muitas reclamações por parte dos educandos ou quando os educadores sentiam que precisavam de mais envolvimento dos mesmos.

É importante apontar que a participação dos educandos no desenvolvimento das atividades não parece corresponder a uma atitude de improviso do professor frente a situações de conflito, mas é utilizada como estratégia pedagógica, organizada desde o planejamento dos professores, como relata a educadora Maria "Eu sempre digo que eles podem dar opiniões, podem interferir, podem sugerir coisas e eu sempre tento ouvir e colocar nos futuros planejamentos.”. Da mesma forma, o educador José diz ouvir os educandos, por isso planeja atividades que elas gostam, mas que também sejam importantes pedagogicamente: "Tem planejamento que tem a necessidade de fazer, por mais que os educandos não gostem muito, mas é preciso fazer, mas se eu sinto que os educandos gostam e veem até mim e buscam aquilo, querem fazer aquilo porque eles acham legal, então eu busco essa atividade porque vai chamar a atenção deles e vai ser muito mais fácil explicar o que eu quero que são os temas propostos, 
me facilita bastante a comunicação deles comigo perante as atividades que eles gostam".

A flexibilidade e abertura à participação dos educandos são, no entanto, relativas, dependendo da perspectiva metodológica do professor, como é o caso do educador Mário, que relata que ouve os educandos apenas quando a atividade "não dá certo" e tenta mudá-la, não de acordo com o que os educandos querem, mas com o que ele próprio acredita ser melhor, sem fugir do seu objetivo inicial: “[...] eu tenho um objetivo, uma proposta da atividade do dia, e se aquela brincadeira para chegar ao objetivo não deu certo, eu acho outra e a gente fala do mesmo assunto no final.".

O reconhecimento da importância de os educandos serem ouvidos no desenvolvimento das ações educativas, e que repercuta no planejamento do professor educador, vai à contramão da perspectiva bastante criticada, embora ainda comum no interior das próprias escolas e de projetos sociais, de que os professores permanecem cegamente fiéis a um planejamento prévio e impositivo, ao qual os educandos devem se enquadrar. Acredita-se que a falta do diálogo, da percepção dos anseios dos educandos e de um planejamento flexível, possa reverter em um embate pouco frutífero no processo de ensino e aprendizagem, no qual o educando busca outros meios para ser ouvido, seja pelo comportamento indisciplinado e, inclusive, na negação em participar, como se pode observar em algumas situações no Projeto investigado.

Sobre esta questão, é interessante a experiência apresentada por Hortélio (1987). A autora descreve as dificuldades de meninos da periferia ficarem dentro da sala de aula e, com o intuito de conseguir estabelecer um diálogo com eles, a professora passa a levá-los em um parque próximo à escola, no qual os alunos construíam brincadeiras a partir do que apanhavam do chão. Ao utilizar esta 
estratégia, a educadora procurou evidenciar a importância de assegurar espaços e tempos de maior liberdade para que os alunos expressem seus interesses, reforçando a necessidade de despertar cotidianamente a delicadeza de saber ouvir e sentir o outro.

Embora possa ser considerada bastante positiva as aberturas para o diálogo e a participação dos educandos identificadas no Projeto investigado, no processo de ensino-aprendizagem, a participação não se dá, apenas na forma de sugestões, solicitações, pedidos e negociações, mas é importante que se torne parte do processo de construção do conhecimento, na forma de elaborações mentais que partam do plano individual e coletivo. Particularmente na área da educação física seria possível pensar tal participação na construção coletiva sobre novos ou diferentes usos do corpo, na elaboração de estratégias táticas em jogos e brincadeira e na reelaboração das mesmas a partir de adição ou subtração de elementos materiais, espaciais, entre outros. A participação ativa e efetiva é condição fundamental para a construção do conhecimento e pressupõe relações e trocas entre os sujeitos, conforme propõe Santos (2002). Pautado na diferenciação entre informação e conhecimento elaborada por Charlot, o autor esclarece que diferente da informação, que é algo externo ao aluno e apreendido numa relação hierárquica entre professor e aluno, o saber é construído nas relações de trocas entre alunos e entre professores e alunos, requerendo atitudes como o ouvir reflexivo, o debate, o diálogo, portanto, a participação ativa e efetiva dos alunos.

A postura de escuta do educador certamente está associada a uma preocupação com uma aprendizagem significativa e também prazerosa, afinal, especialmente no caso das crianças, o brincar é sua atividade principal. Quando questionados sobre seu planejamento, os educadores mencionaram diferentes elementos que os ajudam a 
compor esta tarefa, mas é possível evidenciar esta dupla preocupação, com elementos lúdicos e com a aprendizagem dos conteúdos em si.

Entre as falas, os educadores citam a necessidade de planejar para: atender e ajudar nas dificuldades apresentadas pelos educandos, desenvolver atividades divertidas, tentar ajudar mais quem ainda não sabe jogar, estar atento ao interesse dos educandos e o tempo de duração desse interesse, assim como as diferenças existentes entre as turmas. De forma mais clara, isso pode ser observado no relato de José, que destaca "As atividades são planejadas para o grupo, pra diversão e, principalmente, para aqueles que, tecnicamente, não sabem jogar ainda.”. Quando Maria explica "Eu tento planejar sempre de uma forma que vá alcançar eles e que vá trabalhar algumas necessidades que eu vejo nos educandos, eu penso em atividades práticas que tentem ajudar eles nas dificuldades que eles têm.”. Ou ainda, quando Mário reforça que, além da técnica ou do conteúdo, também se preocupa “[...] no interesse deles, no quanto vai ser divertido e por quanto tempo.”.

Se a participação do educando é importante para que a aprendizagem torne-se mais significativa, a participação do educador no sentido de possuir autonomia no seu planejamento também é importante para o seu maior envolvimento no Projeto. Este aspecto é bastante presente nas falas dos educadores, pois, como afirma Maria “[... a gente tem muita liberdade de criar atividades, de pensar ideias, criar coisas, [...] tem liberdade para criar e inventar.”. O educador Mário corrobora com a importância da liberdade de planejamento, mas enfatiza também a diversidade dos profissionais e a organização do Projeto como fundamentais para sua eficiência: "A facilidade de trabalhar aqui é a organização do Projeto, o qual tem diversos profissionais, diversas áreas, um sistema de reunião e de revisão do trabalho, como se cobra, como se avalia, como se reavalia. Tudo isso favorece a evolução do trabalho.”. 
Conforme se pôde observar no período em que se esteve no campo, um dos aspectos que tem repercutido positivamente no Projeto é a dupla participação, do professor e do aluno. De modo geral, salvo algumas exceções, os educadores dão liberdade para que os educandos manifestem-se de diversas formas e sobre diversas questões, muitas vezes, sem a necessidade de um momento específico para isso, e, na medida do possível, fazem as adaptações discutidas em grupo, sem que os objetivos principais das atividades propostas sejam afetados em sua essência. Por outro lado, mas na mesma direção, os educadores valorizam a sua própria participação no planejamento das atividades e no direcionamento do Projeto, embora haja diretrizes gerais bem estabelecidas e que os temas norteadores deste planejamento sejam estabelecidos pela instituição mantenedora do Projeto.

\section{Os Significados do Projeto: Um Caleidoscópio de Ideias}

Quando se investiga um projeto social percebe-se o quão complexo é o espaço onde ocorrem as interações humanas, visto que, para uma mesma realidade, são tidos os mais diversos olhares e entendimentos. Nesta perspectiva, buscou-se saber mais sobre o significado do Projeto para os educandos e os "achados" foram diversos. Muitos não sabiam ou conseguiam descrever, mas expressavam que o Projeto significava "muita coisa", que é "algo bom e importante" para eles. Destacam também como um local onde eles se sentem bem, como diz Jéssica "Eu estou aqui há bastante tempo, não sei explicar, é um lugar onde me sinto bem.”. O educando César também comenta que "Eu me sinto melhor vindo para o Projeto porque ficar em casa é ruim.”. Assim como César, muitos educandos relatam sobre sua casa e sua família em conversas informais e apontam que lá há pouco a se fazer, que há pouca diversão. 
Alguns educandos, inclusive, emocionam-se ao descrever o Projeto, sentem falta quando não tem no período de férias e em feriados, e não gostariam de sair ao completar 15 anos (limite de permanência no mesmo). A educanda Patrícia explica os motivos pelos quais ela vai ao Projeto: "Porque eu gosto do Projeto, é melhor do que ficar em casa sem fazer nada, só mexendo no celular e no computador.”. Novamente retomamos a pesquisa de Eiras et al. (2010), cujas conclusões apontaram que as crianças participavam dos projetos sociais, educacionais e esportivos, justamente por não quererem ficar em casa, sem "nada" para fazer no contra turno escolar. Outro aspecto levantado pelos autores é que a participação de crianças e adolescentes nos projetos sociais está relacionada com a vontade de aprender e se aperfeiçoar em um determinado esporte, por gostar de esporte, pela descontração, diversão, assim como pelos vínculos sociais, desenvolvimento pessoal e ocupação do tempo disponível.

Em relação aos vínculos sociais, percebe-se que, de fato, alguns educandos parecem estar buscando algo além do esporte e do lazer, como atenção, cuidado e afeto, os quais, segundo algumas falas esporádicas, não têm em casa, devido às próprias conjunturas familiares. Ao mesmo tempo em que os educandos relatam situações de pouco espaço para a convivência familiar, reconhece-se que também há uma busca de aceleração no processo de tornar as crianças adultas e produtivas, minimizando a importância da alegria, do encontro, do diálogo, da amorosidade. Assim como todos os adultos, aqueles que trabalham no Projeto estão submetidos a condições delicadas e a contextos desafiadores que, às vezes, podem torná-los indiferentes às necessidades das crianças e jovens, esquecendo que: "Conceder a palavra às crianças [e jovens] significa, [...] dar a elas as condições de se expressarem.” (TONUCCI, 2005, p. 17). 
Embora nem sempre consigam expressar em palavras seus sentimentos, o que é próprio dos educandos em processo de aquisição e construção do vocabulário, a comparação do Projeto com a casa, sendo a última um espaço que possui poucas alternativas para o tempo livre, fornecem algumas pistas para a reflexão. Apesar de estar centrado no esporte educacional, vislumbra-se que o Projeto tem potencial para desenvolver também o duplo aspecto educativo do lazer: a "educação para e pelo lazer" (MELO, 2008). Utilizando-se do esporte como veículo, o Projeto contribui para uma educação pelo lazer, na medida em que são favorecidos tempos e espaços para discussão de valores e para promoção de um pensar crítico, como ocorre nos momentos de participação dos educandos. Porém, as falas sobre a falta de atividade em casa destacam também a necessidade de uma educação para o lazer, a partir da apresentação da diversidade de conteúdos culturais que possam se concretizar como alternativas de diversão e lazer nos momentos em que estão liberadas do estudo, e no futuro, em momentos que estejam liberadas do trabalho. O Projeto desenvolve isto principalmente pela diversidade de conteúdos esportivos que apresenta aos educandos, mas, talvez possa ser pensada alguma estratégia que ajude as crianças a explorarem o que aprendem no Projeto em ambientes adaptados como a casa e a própria rua.

Compondo este contexto de poucas atividades extraescolares, a família dos educandos é outro aspecto importante a ser levantado, uma vez que há educandos que têm pouco ou nenhum contato com a mãe e/ou o pai, moram com outros parentes, como avós, têm pais separados e, em alguns casos, alguns membros da família estão diretamente envolvidos com o tráfico ou estão presos. Tendo em vista, portanto, que a condição vulnerável dos educandos não se refere apenas à esfera financeira, mas também educativas ou afetivas, muitas crianças e adolescentes encontram no Projeto 
um lugar seguro, que também significa, conforme a fala do educando Márcio: “[...] uma esperança, ele [o Projeto] ajuda várias pessoas, como sair das drogas, não entrar no tráfico.".

Embora os projetos sociais possam contribuir com reflexões e tomadas de decisão em um movimento de emancipação e mudanças de caráter individual, sabe-se que nenhuma garantia quanto ao futuro dos participantes pode ser dada, pois, diferentes fatores influenciam e são influenciados pelas ressonâncias socioculturais e econômicas dos próprios projetos. Assim, mesmo que as falas de educandos e educadores projetem os benefícios do Projeto para a totalidade de aspectos da vida e para um futuro auspicioso, prefere-se pensar no potencial que ele pode ter no tempo presente, contribuindo, senão para a mudança de uma vida, para uma infância e adolescência com experiências enriquecedoras de conteúdos culturais variados. Nesta direção, ao discutir sobre o impacto social do Programa Segundo Tempo no Brasil, no qual há a inclusão de crianças e adolescentes em situações de risco e vulnerabilidade social, Melo; Araújo e Dias (2014) argumenta que eles podem favorecer a formação da cidadania e a valorização da vida, atendendo diferentes necessidades de crianças e adolescentes, não somente as necessidades de caráter físico. Os projetos sociais podem, portanto, ajudar seu público alvo em determinadas situações, porém não são a solução para resolver todos os problemas e não devem substituir o papel do Estado no que concerne à garantia de acesso aos direitos sociais. Isto é, a gestão dos projetos e programas sociais de origem privada deveria envolver a participação estatal ativa, conforme aponta Melo (2008), no sentido de garantir que tais projetos sejam desenvolvidos, a fim de buscar a resolução dos problemas locais e a auto-organização comunitária, diferentemente de se perpetuarem de forma meramente assistencialista. 


\section{Dificuldades a Partir da Percepção dos Professores: Um Longo Caminho a ser}

\section{Percorrido}

Mesmo que se tenha apontado aspectos positivos no desenvolvimento deste Projeto, cabe também refletir sobre os desafios e dificuldades que se encontram naquele contexto. Um dos principais pontos relatados pelos educadores é a dificuldade de conseguir falar com os responsáveis dos educandos, conhecer mais sobre o seu cotidiano a fim de terem mais elementos para "atingirem" ou "acessarem" o educando, como diz Maria "O fundamental é conseguir entendê-los (educandos), entender o contexto das crianças para conseguir alcança-los através das atividades”. Mário também ressalta este aspecto ao explicar que "A maior dificuldade é a cultura deles. [...] porque a gente choca em coisas básicas como leitura que, se já tivessem rodando bem, todas as atividades evoluiriam muito mais.”. Estes relatos aproximamse das ideias de Freire (2001), sobre o fato de que os educadores têm a tarefa de descobrir o que pode ser feito para contribuir com a transformação do mundo, para deixá-lo mais humano, pois diferenças interculturais existem e geram ideologias discriminatórias e de resistência.

Particularmente, ações envolvendo esporte requerem olhares e saberes múltiplos para sua concretização. Desta forma, é pertinente apontar que a existência de uma equipe multiprofissional que trabalha no Projeto como um todo, muito possivelmente, influencie, de forma positiva, nas trocas de saberes ocorridos no interior dos processos avaliativos da ação social, pois diferentes olhares sobre uma mesma situação podem contribuir para uma análise mais ampla, oportunizando soluções mais próximas das realidades dos participantes.

Nesta perspectiva, embora cada profissional tenha seus objetivos traçados, conforme sua especialidade e área de atuação, há objetivos que precisam ser 
delineados em equipe, e assim sendo, podem trazer resultados positivos, auxiliando a superação de determinadas dificuldades. Nesta direção, segundo Gomes (2011), os saberes almejados não englobariam apenas uma dimensão individual de abordagem cognitiva, ou que beneficie determinada habilidade técnica como único parâmetro apropriado. Ou seja, para a efetividade do processo ensino aprendizagem, aqui no caso, em especial, dos esportes, os saberes dos profissionais engajados, precisam envolver outros aspectos, frutos de experiências coletivas, sendo influenciados por inúmeros fatores. Embora Gomes (2011) esteja se reportando em suas discussões à formação profissional em lazer, estas reflexões podem ser extrapoladas para o contexto mais amplo da pesquisa ora discutida.

O educador Mário também cita o local onde o Projeto é realizado, que, algumas vezes, limita o trabalho a ser desenvolvido, além do lanche fornecido pelo Projeto: "Eu não gosto da maneira que o Projeto fica refém do clube, parece que as crianças merecem menos de estar aqui do que os colaboradores. Acho que o lanche poderia ser melhor. Deveria ter uma nutricionista para pensar em uma educação alimentar melhor.”.

São inúmeras as situações de projetos sociais, como o aqui apresentado, os quais se concretizam a partir da terceirização de espaços. Há que se adaptar aos recursos ali disponíveis, realidade que, nem sempre, é a melhor para seus usuários. Contudo, ainda assim, é necessário reconhecer a importância de tal iniciativa, com vistas a atingir um número maior de pessoas e suas necessidades. Idea esta corroborada por um dos estudos de Melo (2002), ao apontar os escassos espaços públicos próprios para as atividades esportivas nas regiões de periferia. Embora o espaço físico deste núcleo do Projeto seja terceirizado, inviabilizando seu uso permanente e público pela comunidade, apresenta condições adequadas para que as 
ações do Projeto se desenvolvam com qualidade, contrariando iniciativas que se contentam em oferecer serviços, mesmo que básicos e pontuais, em precárias condições.

Os outros dois educadores entrevistados expressam preocupação com alguns aspectos da formação dos educandos, como o fato de que muitos têm dificuldades de ler e escrever (mesmo isto não sendo tarefa direta do projeto), e com o futuro dos mesmos após o Projeto, o que se pode perceber em suas falas. Maria diz "Eu sinto angústia em não poder ajudar melhor eles, [...] é bem angustiante ver alguns adolescentes sem saber ler e escrever, sem saber fazer operações matemáticas básicas.” E José expressa: "Eu acho que a gente faz muito bem essa parte dos sete aos 15 anos, mas sempre vai ficar aquela pergunta: depois dos 15, para onde aquele educando vai? Fico preocupado com o que vai acontecer.".

Nesta perspectiva, Armani (2001) apresenta as limitações dos projetos sociais, entre elas a maior preocupação com eficiência e controle do que com a efetividade, a flexibilidade e o aprendizado. Qual enfoque os projetos sociais devem, de fato, assumir, vislumbrando o "futuro" e os encaminhamentos que se almejam? O autor ainda enfatiza o risco de projetos sociais serem substitutos da ação social do Estado, com tempo cronometrado e metas, muitas vezes, intangíveis.

A educadora Maria menciona a mudança que os educandos têm em suas vidas, o resultado do trabalho desenvolvido no Projeto: "É a maneira que trabalhamos, tentamos ajudar da maneira que conseguimos e o mais gostoso é esse contato com os educandos. É poder ver a diferença que a gente faz na vida deles, a diferença de um carinho, e ver a evolução deles. Eles entram aqui de uma maneira e trabalhamos tanto com aquele educando que vemos um resultado muito gratificante. O que eu mais gosto é ver o resultado nos educandos.”. Embora alguns resultados não possam ser 
diretamente vislumbrados no desempenho escolar dos educandos, os educadores salientam os avanços das crianças e dos adolescentes no que tange a socialização, a afetividade, o respeito e no conhecimento de bens culturais, como destaca o educador José: “[...] todas aquelas crianças que estavam jogando tênis, nunca iam conhecer esse esporte. [...] sei de todos os valores que a pessoa que joga ganha com isso. [...] (os educandos) nunca na vida teriam a chance de segurar uma raquete e jogar dentro de uma quadra de tênis".

No cenário contraditório e conflituoso de desenvolvimento de projetos sociais, fica evidente, seja na visão dos educandos ou dos educadores, que o Projeto investigado neste estudo possui significativo potencial em relação a contribuições para reflexões e tomadas de decisão que podem, ou não, influenciar em transformações sociais e oportunidades que crianças e adolescentes de uma comunidade periférica não teriam, caso não participassem desta ação social. Ou seja, os participantes deste estudo não estão à margem da reprodução de críticas vividas no interior dos projetos sociais, no entanto, apresentam interessante potencial mobilizador para transformações socioculturais.

Corroborando com esses dados há relatos dos educadores, que fazem parte do Projeto há anos, acerca das mudanças percebidas em diversos educandos. Este movimento de ensinar e aprender mutuamente, tanto educandos quanto educadores, exerce o que Freire (2001) afirma sobre sermos seres programados para aprender e ensinar, o que faz parte da essência humana, histórica e social. Neste processo, o aprendizado é permanente, na finitude do ser humano e na consciência de sua finitude.

Ao serem abordados esses aspectos trazidos pelos educandos e educadores, por meio de observações e entrevistas, nota-se que o Projeto tem movimento, tem 
gente correndo, tem gente brincando, tem bolinhas de tênis espalhadas, tem gente rindo, gente chorando, tem gente tropeçando. Enfim, ele é feito de gente e para gente, por isso aparecem contradições, emoções, sentimentos, aprendizagens. Desta forma, não se procurou o estabelecimento de verdades, mas, sim, de diálogos e reflexões.

\section{Fechando as Janelas, Mas Mantendo as Portas Abertas}

Este estudo evidenciou que o Projeto Social investigado, visto sob o olhar de crianças e adolescentes participantes, complementado pela percepção dos profissionais envolvidos, trata-se de um espaço tempo, no qual elas ensinam e aprendem diversos conteúdos e valores, fundamentais para seu desenvolvimento. Identificou-se que os conteúdos trabalhados neste Projeto são diversificados, garantindo a participação das crianças, embora se saiba que dificilmente será possível atender a totalidade dos interesses, devido à diversidade correspondente às práticas esportivas e culturais.

Embora as crianças não reconheçam a sua participação no desenvolvimento das atividades, elas são ouvidas pela maioria dos educadores. Esta percepção de "não participação" de algumas crianças pode ser atribuída às exigências de organização do próprio Projeto, que se estende a um coletivo. São vários os significados que as crianças e os adolescentes atribuem ao Projeto, no entanto, para além dos relatos, das experiências vividas, e das aprendizagens efetivadas, percebe-se a alegria que se manifesta nos sorrisos, nos abraços, nos olhares, entre outros sinais que representam a gratidão das trocas entre educandos e educadores. 


\section{REFERÊNCIAS}

ARMANI, D. Como elaborar projetos? Guia prático para elaboração e gestão de projetos sociais. Porto Alegre: Tomo Editorial, 2001.

BARDIN, L. Análise de conteúdo. Lisboa: Edições 70, 2009.

BRACHT, V. Sociologia crítica do esporte. Ijuí: Unijuí, 2003.

DARIDO, S. C. Esporte e educação: uma relação imprescindível. In: GOELLENER, S.V.; SOARES, L.S.; CARVAlHO, M. A. Á. (Org.). Programa Segundo Tempo: memória, experiências, avaliação e perpectivas no encontro das equipes colcaboradoras. Maringá: Eduem, 2012. p.81-106.

EIRAS, S.B. et al. Objetivo da Oferta e da Procura de Projetos Sócio-Esportivos. Licere, Belo Horizonte, v.13, n.3, p.1-24, set. 2010.

FREIRE, P. A importância do ato de ler: em três artigos que se completam. São Paulo: Cortez, 1989.

. Política e educação: ensaios. 5. ed. São Paulo: Cortez, 2001.

GOMES, C.L. Lazer e formação profissional: saberes necessários para qualificar o processo formativo. In: FORTINI, Janice L.; GOMES, Christianne L.; ELIZADE, Rodrigo (Org.). Desafios e perspectivas da educação para o lazer. Belo Horizonte: Editorial SESC/Otium, 2011, v.1, p.33-46.

GONZÁLES et al. Nas pegadas do esporte educional. In: MARINHO, A.; NASCIMENTO, J.V; OLIVEIRA, A.A.B.(Org.). Legados do esporte brasileiro. Florianópolis: Ed. da UDESC, 2014. p.35-43.

HORTÉLIO, L. História de uma manhã. São Paulo: Massao Ohon, 1987.

LAKATOS, E.M.; MARCONI, M.A. Metodologia científica: ciência e conhecimento científico, métodos científicos, teoria, hipóteses e variáveis. 5. ed. São Paulo: Atlas, 2007.

MELO, V.A. "Projetos sociais" de esporte e lazer: reflexões, inquietações, sugestões. Revista Quaderns d'Animació i Educació Social, Sagunto, n. 7, p.1-24, jan. 2008.

. Manual para otimização da utilização de equipamentos de lazer. Rio de Janeiro: Serviço Social do Comércio/Rio de Janeiro, 2002.

MELO, J. P.; ARAÚJO, A. C.; DIAS, M. A. Múltiplas ações e diversidade de corpos na inclusão social pelo esporte: contribuição do Programa Segundo Tempo. In: MARINHO, A.; NASCIMENTO, J.V.; OLIVEIRA, A.A.B. Legados do esporte brasileiro. Florianópolis: Editora da UDESC, 2014. p. 455-485.

MENICUCCI, Telma. Políticas públicas de lazer: questões analíticas e desafios políticos. In: ISAYAMA, Hélder; LINHALES, Meily (Org). Sobre lazer e política: maneiras de ver, maneiras de saber. Belo Horizonte: Ed UFMG, 2006. p. 136-164. 
MINAYO, M.C.S. (Org.). Pesquisa social: teoria, método e criatividade. 20. ed. Petrópolis: Vozes, 2012.

NEIRA, M.G. Programas de educação pelo esporte: qual formação está em jogo?. Movimento \& Percepção, Espirito Santo do Pinhal, v. 10, n.14, p. 59-66, jan./jun. 2009.

OLIVEIRA, L. Os excluídos "existem"? Notas sobre a elaboração de um novo conceito. Revista Brasileira de Ciências Sociais, n. 33, p. 49-61, fev. 1997.

OVIEDO R. A. M.; CZERESNIA D. O conceito de vulnerabilidade e seu caráter biossocial. Interface - Comunicação, Saúde, Educação, Botucatu, v.19, n.53, p. 237250, jun. 2015. Disponível em: https://www.scielo.com.br . Acesso em: 05 jun. 2002.

PEREIRA, M.A.P. Casa Redonda: uma experiência em educação. São Paulo: Livre, 2013.

SILVEIRA, J. Considerações sobre o esporte e o lazer: entre direitos sociais e projetos sociais. Licere, Belo Horizonte, v. 16, n. 1, p. 1-22, mar. 2013.

SANTOS. J. C. A participação ativa e efetiva do aluno no processo ensinoaprendizagem como condição fundamental para a construção do conhecimento. Mestrado. Universidade Federal do Rio Grande do Sul. Faculdade de Educação. Programa de Pós Graduação em Educação. 2002.

TONUCCI, F. Quando as crianças dizem: agora chega! Porto Alegre: ARTMED, 2005.

TUBINO, M.J.G. O que é o esporte. São Paulo: Brasiliense, 2006.

Estudos brasileiros sobre o esporte: ênfase no esporte-educação. Maringá: Eduem, 2010.

ZALUAR, A. Cidadãos não vão ao paraíso. São Paulo: Escuta, 1994.

ZINGONI, P. Marco Lógico: uma metodologia de elaboração, gestão e avaliação de projeto social de lazer. In: PINTO, L.M.S.M.; MARCELLINO, N.C.; ZINGONI, P. (Org.). Como fazer projetos de lazer: elaboração, execução e avaliação. 3. ed. Campinas: Papirus, 2007. p. 13-79.

\section{Endereço das Autoras:}

Liliana Flora

Serv. Manoel Antônio Vieira, 61 - Costeira do Pirajubaé

Florianópolis - SC - 88.047-103

Endereço Eletrônico: liliana.flora@hotmail.com

Miraíra N. Manfroi

Rua dos Canteiros, 289 - Bairro Rio Tavares

Florianópolis $-\mathrm{SC}-88.063-680$ 
Endereço Eletrônico: mira_nm@hotmail.com

\title{
Verônica Werle
}

Rua Lauro Linhares, 1346, Ap. 1006. Trindade.

Florianópolis - SC - 88.036-002

Endereço Eletrônico: vewerle@yahoo.com.br

\author{
Alcyane Marinho \\ Rua Vereador Ramon Filomen, 357, apto. 1001 torre 1 \\ Parque São Jorge \\ Florianópolis - SC - 88.034-495 \\ Endereço Eletrônico: alcyane.marinho@hotmail.com
}

